\title{
Hydropyrolysis as a new tool for radiocarbon pretreatment and the quantification of black carbon.
}

Authors and affiliations: P. L. Ascough ${ }^{1 *}$, M. I. Bird ${ }^{1}$, F. Brock ${ }^{2}$, T.F.G. Higham ${ }^{2}$, W.

Meredith $^{3}$, C. E. Snape ${ }^{3}$, C. H. Vane ${ }^{4}$.

${ }^{1}$ Department of Geography and Geoscience, University of St. Andrews, Irvine Building, St. Andrews, Fife, KY16 9AL, UK.

${ }^{2}$ Oxford Radiocarbon Accelerator Unit, Research Laboratory for Archaeology and the History of Art, Dyson Perrins Building, University of Oxford, Oxford OX1 3QY, UK.

${ }^{3}$ School of Chemical and Environmental Engineering, University of Nottingham, NG7 2RD, UK

${ }^{4}$ British Geological Survey, Kingsley Dunham Centre, Keyworth, Nottingham NG12 5GG, UK.

*Corresponding author. Tel.: +44 1334 463936; fax: +44 1334 463949. E-mail: pla1@standrews.ac.uk (P. L. Ascough).

\section{Abstract}

The first results concerning the potential of hydrogen pyrolysis (hypy) as a new tool for the quantification and isolation of Black Carbon (BC) for radiocarbon analysis are reported. BC is a highly stable form of carbon, produced during pyrolysis of biomass to materials such as charcoal. Isolation and quantification of this component is therefore of great interest in radiocarbon measurement, particularly for more ancient samples, where contamination issues become more critical. Hypy has been demonstrated to reliably separate labile and refractory carbonaceous sample components for engineering and geological applications, but its potential in ${ }^{14} \mathrm{C}$ geochronological investigation has previously been unexplored. Here, we test the hypy technique using a selection of soil standard samples and ancient charcoals from deposits of geological and archaeological significance. The results show that hypy can effectively and reproducibly isolate different carbon fractions within a variety of sample types and thus has the potential to provide a rapid and robust pre-treatment technique for radiocarbon analysis. Hypy has the additional advantage that the non-BC fraction removed from a sample can be quantitatively collected for subsequent further analysis. The technique represents a promising new approach not only for ensuring reliable decontamination of 
pyrogenic carbon samples prior to radiocarbon dating, but also for $\mathrm{BC}$ quantification in a variety of environmental matrices.

\section{Keywords}

Black Carbon, Hydropyrolysis, Radiocarbon, charcoal

\section{Introduction}

Black Carbon (BC) is produced from the thermal degradation of biomass under conditions of restricted oxygen (pyrolysis), a process which transforms the starting material into a range of products, including soot, char and charcoal (Preston and Schmidt, 2006). As biomass undergoes pyrolysis, the $\mathrm{H}, \mathrm{N}, \mathrm{O}, \mathrm{S}$ content of the material decreases and the original molecular carbon structure is rearranged into condensed aromatic ring configurations (Tang and Bacon, 1964; Eckmeier et al., 2007), which are highly stable, and hence potentially resistant to environmental degradation. $\mathrm{BC}$ is therefore defined chemically as having both high aromaticity and high resistance to oxidative degradation, with estimates for the half-life of pyrolyzed carbon in soils extending to 5-7ky (Preston and Schmidt, 2006). BC exhibits both global distribution and locally high abundance in soils and sediments, for example, in some soils up to $35 \%$ of total organic carbon content is comprised of charred biomass (Skjemstad et al., 2002). BC also plays a dynamic role within soil systems, influencing pedogenic development, and duration of BC storage within soils appears influenced by factors of climate, deposition environment, and land use (Czimczik and Masiello, 2007). This means that $\mathrm{BC}$ is an important source of geochronological data, commonly submitted for radiocarbon $\left({ }^{14} \mathrm{C}\right)$ measurement, in the form of both isolated samples of pyrolysed material (e.g. charcoal fragments), and as a component within bulk samples (e.g. soils, marine sediments and aerosols).

The removal of extraneous carbonaceous contaminants is essential prior to ${ }^{14} \mathrm{C}$ measurement, and standard pre-treatment for pyrogenic carbon material involves sequential extraction with acid and base reagents (ABA method), to remove soil carbonates and organic acids. While contaminant removal is non-selective (Santos et al., 2001), exact pre-treatment conditions vary between laboratories, and it is not routine to empirically assess the amount or chemical composition of the contaminants removed. The ABA treatment appears rapid and effective for the majority of samples. However, elimination of contamination becomes more critical as 
sample age increases, and confidence in the measured ${ }^{14} \mathrm{C}$ activity of material closer to the limit of the ${ }^{14} \mathrm{C}$ method depends upon confidence in the ability of a pre-treatment to exhaustively remove any extraneous carbonaceous contamination. In some environments the ABA pre-treatment appears not to successfully remove all contaminants (Gillespie et al., 1992). For example, analysis of charcoal associated with deposits from a tropical volcano indicated only partial removal of residue from the decomposition of modern plant rootlets using the ABA technique (Harkness et al., 1994). In addition, pyrolysed biomass such as charcoal has a high affinity for, and will readily adsorb, compounds such as phenols and polycyclic aromatic hydrocarbons (Cornelissen and Gustafsson, 2004; Sander and Pignatello, 2005; Wang et al., 2001). The magnitude of organic chemical sorption by BC-containing materials is non-linear, therefore may be considerably larger than that exhibited by other soil organic matter (Cornelissen et al., 2005). Soil microbial communities also interact with pyrolysed biomass in soils (e.g. Warnock et al., 2007), with enhanced soil biota activity suggested as a result of factors such as availability of carbon and nutrients sorbed onto the charcoal surface (Pietikäinen et al., 2000), or through the provision of micro-habitats within the char structure itself (Wardle et al., 1998). In such cases, exhaustive removal of all contaminants is time-consuming, and it may be difficult to remove components sorbed or weakly bonded to the sample matrix without completely destroying the sample.

As BC represents carbon fixed by pyrolysis of biomass at the time of an event of interest for dating, the ability to isolate and measure this component is of considerable significance for ${ }^{14} \mathrm{C}$ geochronology. This is applicable both for age measurement in terms of palaeoenvironmental events and in the form of tracer studies for environmental processes, for example, in quantification of sedimentary turnover rates. An alternative pre-treatment for samples older than 30-35 ka BP, or where conventional ABA methods do not satisfactorily remove contaminants, is to remove all material apart from the most chemically resistant fraction. One such method replaces the final acid wash of the ABA treatment with wet oxidation, followed by stepped combustion (ABOX-SC). This technique allows analysis of the most chemically resistant fraction of carbonaceous samples (Bird et al., 1999), and has been used in age measurement of samples up to 55 ka BP (Santos et al., 2001; Turney et al., 2001). Issues with this method include the potential release of volatile sulphur compounds

100 during evolution of sample $\mathrm{CO}_{2}$, resulting from the use of $\mathrm{H}_{2} \mathrm{SO}_{4}$ in the oxidation step, 101 inhibiting graphitization of the sample (Santos et al., 2001). The main issue with the ABOX-

102 SC method however, is the difficulty of identifying the point at which contaminants are 
removed and further oxidation results in degradation of the BC structure itself. The amount of material isolated as $\mathrm{BC}$ via chemical oxidation varies depending upon the source material and applied oxidation time (Knicker et al., 2007). For example, procedural variations in oxidation by acidified dichromate for $\mathrm{BC}$ isolation within a systematic international inter-comparison study resulted in $\mathrm{BC}$ determinations from 1.1-8.0 and 0.6-2.2 $\mathrm{g} \mathrm{kg}^{-1}$ in two soils, along with variations in internal reproducibility of a factor of at least 2 (Hammes et al., 2007). The effective use of $\mathrm{BC}$ for ${ }^{14} \mathrm{C}$ measurement therefore depends upon the ability to reliably isolate and analyse this material from a range of environmental matrices. Attempts to improve current analytical techniques are complicated by the fact that methodological developments for $\mathrm{BC}$ isolation are ongoing, and that various existing methodologies define $\mathrm{BC}$ according to

113 different criteria, depending upon the part of the pyrogenic carbon continuum they target 114 (Preston and Schmidt, 2006). Some methods may also result in methodological artefacts, for example, Simpson and Hatcher (2004) found that a thermal oxidative method for BC quantification inadvertently produced a component of pyrolysed organic matter subsequently defined as BC during analysis of initially BC-free material. Research aims have therefore included the development of methodologies that reduce the potential for artefacts and allow greater accuracy in BC quantification (e.g. Gelinas et al., 2001).

Extensive research benefits are therefore offered by a technique that can effectively and reproducibly isolate and quantify purified $\mathrm{BC}$ from a wide range of sample matrices. In this paper, we explore the potential of a new method which holds great promise in this regard, known as hydropyrolysis (hypy). Hypy uses pyrolysis assisted by high hydrogen pressures (>10 MPa) with a dispersed sulphided molybdenum (Mo) catalyst to separate labile and refractory carbonaceous sample components. This process has been used extensively in analysis of terrestrial kerogens where overall conversions of close to $100 \%$ are achieved for thermally labile material (e.g. Roberts et al., 1995), the principal product being a dichloromethane-soluble oil. Further, it has been shown that the hydrocarbon products of hypy are released in high yields (Love et al., 1997), with the advantage that it should be possible to identify and characterize the non-BC contaminants in samples at a molecular level, including analysis of ${ }^{14} \mathrm{C}$ activity. Because stereochemical rearrangements accompanying hypy are minimal due to the high pressure hydrogen, the neoformation of $\mathrm{BC}$ that occurs in normal thermal oxidation is largely suppressed, meaning that interference from

135 formation of $\mathrm{BC}$ during the analytical procedure should not prove to be a major issue (Love 136 et al., 1995). 
138 In general, hypy offers a potential means to discriminate between bound and adsorbed 139 organic species. As a result of this, the technique has been used to remove adsorbed products, 140 facilitating analysis of organic carbon in samples even up to Archaean age (Brocks et al., 141 2003). Thus far, however, the potential application of hypy for the quantification and 142 isolation of $\mathrm{BC}$ for ${ }^{14} \mathrm{C}$ measurement remains unexplored. In this study, we have used a range 143 of samples containing BC to assess the use of hypy for this purpose, of various antiquities 144 and from different soil matrices. One key factor is whether it is possible to determine the 145 operational conditions under which removal of the labile organic matter is complete. At this 146 point, further hydrogen pyrolysis would result in degradation of the purified $\mathrm{BC}$ itself via 147 hydrogasification. We have therefore assessed the reproducibility and reliability of the 148 method to isolate $\mathrm{BC}$ from soils and charcoal, and used ${ }^{14} \mathrm{C}$ measurement of the hypy residue 149 and removed products to test its potential utility as a pre-treatment procedure for ${ }^{14} \mathrm{C}$ analysis 150 of charcoal. 


\section{Materials and methods}

\subsection{Samples}

Information on the samples selected for this study is provided in table 1. These include three ancient charcoals obtained from natural and archaeological deposits, two of which are from deposits of key geological and archaeological significance, close to the radiocarbon dating boundary, with previously established ${ }^{14} \mathrm{C}$ ages. The first of these charcoal samples (MA) was recovered in situ from paroxysmal flow deposits source from the Maninjau caldera in westcentral Sumatra. Isothermal plateau and diameter corrected fission-track techniques place the flow deposits at 50,000 $\pm 3000 \mathrm{BP}$ (Alloway et al., 2004). For MA, the previous ${ }^{14} \mathrm{C}$ measurements included pre-treatment by conventional ABA and ABOX-SC pre-treatment, giving ages of 51,100 to $52,300{ }^{14} \mathrm{C} \mathrm{BP}$, and earlier assessments of infinite ages $>40,000{ }^{14} \mathrm{C}$ BP (Table 1).

The second charcoal sample, CHA, was recovered from a hearth deposit in the Megaceros gallery of Chauvet Cave, in the Ardeche Valley of France. Human activity in the cave included the oldest parietal art thus recorded, dated to ca. 32,000 years BP (Clottes et al., 1995, Valladas et al., 2001 and Valladas et al., 2005), and along with charcoal, associated deposits containing animal skeletal remains, animal and human footprints, and flint and ivory artefacts (Garcia, 2005 and Geneste, 2005). The charcoal sample obtained from material excavated at Chauvet Cave (CHA) had previously been subjected to ${ }^{14} \mathrm{C}$ measurement as part of a laboratory intercomparison exercise (Cuzange et al., 2007), as part of which the ABOXSC pre-treatment methodology was used for some measurements, yielding ages of 32,350 \pm $210{ }^{14} \mathrm{C}$ BP (OxA-X-2130-47) for the oxidation stage only, 32,080 $\pm 200{ }^{14} \mathrm{C}$ BP (OxA-X2131-14) for oxidation followed by $300^{\circ} \mathrm{C}$ pre-combustion and $31,810 \pm 190{ }^{14} \mathrm{C}$ BP (OxA-X2130-48) for oxidation followed by $630^{\circ} \mathrm{C}$ pre-combustion. The results of multiple ${ }^{14} \mathrm{C}$ measurements on charcoal samples from the hearth from which CHA was sampled yielded an average age of $32,030 \pm 120{ }^{14} \mathrm{C} \mathrm{BP}$ (Cuzange et al., 2007).

The final charcoal sample, CAS, was recovered from deposits at the site of Castro de Santiago, a hilltop settlement with enclosures, located in Fornos de Algodres, Guarda district, central Portugal. This sample itself had not previously been ${ }^{14} \mathrm{C}$-dated, however attached 
enclosures at the archaeological site from which the material was obtained have been established to date to around 5000-4500 calendar years before present (Valera, 1997).

Along with charcoal, three modern soil samples were selected for analysis (table 1), in order to test the suitability and reproducibility of hypy for quantifying soil BC, using well characterized standard soil material. Two of these (VER and MO), were produced and distributed under the auspices of the International Steering Committee for Black Carbon Reference Materials. VER is a vertisol, a sandy clay soil, collected at $0-10 \mathrm{~cm}$ depth from the region of Toowoomba in Queensland, Australia by CSIRO Land \& Water, Australia, and is described in detail in Skjemstad et al., (1999) and Schmidt et al., (2001). MO is a mollisol, a sandy soil, developed on loess in the region of Hildesheim-Braunschweig, northern Germany. The sample was collected at $20-60 \mathrm{~cm}$ depth, by the University of Cologne, and is described in detail in Schmidt et al. (1999).

The $\mathrm{BC}$ content of these two soils was measured at several laboratories as part of the $\mathrm{BC}$ international inter-comparison where a range of methods were used to quantify BC (Hammes et al., 2007). As mentioned above, the results varied widely depending upon methodological conditions, however overall MO was found to have slightly lower BC content than VER (Table 1). The final soil sample (BGS), is a silty clay soil, from an area of anthropogenically disturbed ground in Glasgow, Scotland. The nature of the disturbance included ash deposition, indicating recent burning, and therefore a BC contribution to the sample composition. This sample was collected at $0-15 \mathrm{~cm}$ depth by the British Geological Survey in 2001 (Rawlins et al., 2008), where the BC content (24.3 $\left.\mathrm{g} \mathrm{kg}^{-1}\right)$ was determined by a modified chemothermal oxidation method (after Kuhlbusch, 1995).

\subsection{Hypy procedure}

210

211 Fixed bed hypy tests were performed using the apparatus shown in figure 1, with the products

212 collected in a silica filled trap (Meredith et al., 2004) immersed in an ethanol dry ice slush 213 trap at $-72^{\circ} \mathrm{C}$. The procedure is described in detail in Love et al., (1995; 1997). Briefly, the 214 samples were first loaded with the Mo catalyst (5\% by weight) using an aqueous/methanol $2150.2 \mathrm{M}$ solution of ammonium dioxydithiomolybdate $\left[\left(\mathrm{NH}_{4}\right)_{2} \mathrm{MoO}_{2} \mathrm{~S}_{2}\right]$, and then pyrolysed 216 with resistive heating from $50^{\circ} \mathrm{C}$ to $250^{\circ} \mathrm{C}$ at $300^{\circ} \mathrm{C} \mathrm{min}{ }^{-1}$, and then from $250^{\circ} \mathrm{C}$ to the final 
217 temperature (between 400 and $600^{\circ} \mathrm{C}$ ) at $8^{\circ} \mathrm{C} \mathrm{min}^{-1}$, under a hydrogen pressure of $15 \mathrm{MPa}$. A

218 hydrogen sweep gas flow of $5 \mathrm{~L} \mathrm{~min}^{-1}$, measured at ambient temperature and pressure,

219 ensured that the products were quickly removed from the reactor vessel. Three replicate tests

220 to a final hold temperature of $500^{\circ} \mathrm{C}$ were performed on the MO soil sample to assess

221 reproducibility of the hypy technique.

222

\subsection{Determination of non-BC removal using hypy}

224

Tests were performed in order to ascertain whether it was possible to observe a plateau with increasing temperature corresponding to a temperature interval after the removal of labile organic matter is complete (i.e. non-BC material, mainly lignocellulosic) and before the onset of hydrogasification of the BC itself to methane (e.g. Suzuki et al., 1986; Bolton et al., 1987; Xua et al., 2003). This involved monitoring the residual Total Organic Carbon (TOC) content of VER and BGS reference soils and charcoal sample MA as a function of the peak temperature used in each hypy test. Hypy temperature was varied between 400 and $600^{\circ} \mathrm{C}$ at increments of $25^{\circ} \mathrm{C}$ for the soils and between 500 and $600^{\circ} \mathrm{C}$ for the charcoal. For MA, the total mass loss of the sample was determined for each experiment. The TOC of samples were measured using a $\mathrm{CO}_{2}$ coulometer (UIC ${ }^{\circledR}$ Coulometrics Inc., IL, USA), which measures the $\mathrm{CO}_{2}$ generated by combustion of the sample at $1000^{\circ} \mathrm{C}$ in a stream of oxygen by titration against ethanolamine. For each sample the average of two replicate analyses was taken.

\subsection{Hypy procedure for ${ }^{14} \mathrm{C}$ measurement}

After the hypy treatment the sample residue and the hypy product, cryogenically collected on silica (i.e. removed contamination), were AMS dated at the ORAU (Oxford Radiocarbon Accelerator Unit), University of Oxford. ${ }^{14} \mathrm{C}$ measurements were also made of aliquots of the untreated charcoal and charcoal treated with $0.5 \mathrm{M} \mathrm{HCl}$ for decarbonation (as described below). For $\delta^{13} \mathrm{C}$ measurements, samples were combusted and analyzed using a Europa Scientific IRMS system interfaced to a Roboprep CHN sample converter unit, operating in continuous flow mode using helium as the carrier gas. Stable isotope ratios are expressed in $\%$ relative to $\mathrm{vPDB}$ where mass spectrometric precision is $\pm 0.2 \%$. The ${ }^{14} \mathrm{C}$ content of charcoal reflects that of atmospheric sources at the time the plant grew, and thus reflects a relatively constrained time interval. In this instance, the event of interest for dating, (i.e. the 
date of plant tissue formation), corresponds to a single, constrained and hence 'dateable' event. This contrasts with the BC component of the soil samples, as it is likely that this represents a mix of inputs from different sources over an extended but unknown period.

253 Therefore, while the soil samples represent well-characterized standard materials, they are 254 otherwise uncontextualized, limiting our ability to interpret a ${ }^{14} \mathrm{C}$ measurement of these samples following hypy in a meaningful manner.

257 The charcoal samples for ${ }^{14} \mathrm{C}$ determination were crushed to pass a $500 \mathrm{~mm}$ mesh, and an aliquot of the crushed material (i.e. with only physical treatment) was taken for dating as representative of the untreated sample. The remaining sample material was then placed in

$2600.5 \mathrm{M} \mathrm{HCl}$ overnight to remove soil carbonates. Following decarbonation the sample material was washed three times in deionized water before drying to constant weight at $50^{\circ} \mathrm{C}$. An aliquot of the decarbonated charcoal was subjected to standard ABA pre-treatment at the University of Oxford (c.f. Wild et al., 2008). This consists of an acid wash to remove sediment carbonates, a base wash to remove organic acid contaminants such as humic acids and a final acid wash (to remove any atmospheric $\mathrm{CO}_{2}$ which may have been absorbed by the sample during the base wash). In between each wash the samples were thoroughly rinsed with ultrapure water.

Aliquots of the decarbonated charcoal samples were also taken for hypy treatment. The heating regime was designed to ensure optimum removal of all lipids, proteins and lignocellulosic material in the sample, leaving only the purified $\mathrm{BC}$ fraction, and comprised heating as described above with final holding at $600^{\circ} \mathrm{C}$ for two minutes. It is possible that at the higher temperature, some hydrogasification of the $\mathrm{BC}$ structure itself could occur but, as will be discussed, the extent of hydrogasification at this temperature is not considered to be significant. Instead, a higher temperature, more aggressive hypy regime was targeted at removal of labile carbonaceous sample fractions, rather than $\mathrm{BC}$ quantification. The weights pyrolysed for MA, CAS and CHA were 306, 273 and $84 \mathrm{mg}$ respectively, and to each sample catalyst was loaded at 5\% weight Mo. 


\section{Results}

281

282

\subsection{BC determination via hypy}

283

284

The change in residual TOC as a function of temperature for the VER and BGS reference soils and the MA charcoal is presented in table 2 and figures 2 and 3. Mass losses during hypy of the soil samples were c. $2-3 \% \mathrm{w} / \mathrm{w}$. Figure 2 shows the same trend of decreasing carbon content until $550^{\circ} \mathrm{C}$ for VER and $525^{\circ} \mathrm{C}$ for BGS, corresponding to the loss of carbon from the labile (i.e. non-BC) organic matter in the soil. Following this phase a plateau in TOC is reached. This is consistent with other hypy studies for lignocellulosic material which has indicated that up to $100 \%$ conversion to volatile products is achieved by approximately $500^{\circ} \mathrm{C}$ (Rocha et al., 1999). At $600^{\circ} \mathrm{C}$, following the plateau phase, there is the beginning of a further loss of carbon which marks the onset of char hydrogasification to yield methane. The residual TOC content over the plateau region is taken as the $\mathrm{BC}$ content of the sample material, and represents the conditions under which the total $\mathrm{BC}$ portion of a sample may be recovered. For VER at $550^{\circ} \mathrm{C}$ this suggests a BC content of $6.6 \mathrm{~g} \mathrm{~kg}^{-1}$ which is consistent with, but at the upper end of values obtained for this sample in the $\mathrm{BC}$ inter-comparison study (e.g. $4.7 \pm 2.9 \mathrm{~g} \mathrm{~kg}^{-1}$ for dichromate oxidation (Hammes et al., 2007)). For the BGS sample at $550^{\circ} \mathrm{C}$ the estimated $\mathrm{BC}$ content is $28.5 \mathrm{~g} \mathrm{~kg}^{-1}$, which is comparable with previous $\mathrm{BC}$ determination for this sample of $24.3 \mathrm{~g} \mathrm{~kg}^{-1}$. These results provide strong evidence that at temperatures above c. $500^{\circ} \mathrm{C}$ non-BC sample components are effectively removed.

Clearly, depending where a particular sample lies on the broad continuum of compositions, some weight loss might be anticipated during hypy, especially those samples that have not been subjected to high temperature during pyrolysis. This is supported by the tests on the MA charcoal sample, where sample weight loss during hypy increases from $14.1 \%$ by $500^{\circ} \mathrm{C}$ to $26.8 \%$ by $600^{\circ} \mathrm{C}$ where it then appears to level off (figure 3). Much of the weight loss below $500^{\circ} \mathrm{C}$ is due to oxygen removal which gives rise to the increase in the TOC content relative to the initial (catalysed) sample (table 2) but some carbon loss from the sample itself has also occurred. Most of the mass loss of the MA sample between 500 and $575^{\circ} \mathrm{C}$ is also due to oxygen as indicated by the fairly constant level of TOC remaining over this temperature range. However, a small quantity of tar was collected, which may be derived

312 from the decomposition of highly aromatic humic acids (Haumaier and Zech, 1995). The 
313 apparent plateau in the MA sample still evident at $600^{\circ} \mathrm{C}$ could represent a delayed onset of

314 hydrogasification in relation to the two soil samples. The uncertainty in the BC determination 315 arising from this extended plateau however is clearly very small compared to the high 316 variations described earlier for oxidative procedures.

\subsection{Reproducibility}

The TOC content of the uncatalyzed MO soil sample prior to hypy treatment was $2.00 \%$. After the hypy treatment, triplicate analyses of the sample TOC content gave a final average value of $0.76 \pm 0.02 \%$ for identical run conditions of a single sample. This indicates a high degree of measurement precision can be achieved with the hypy methodology, which compares favourably with that achieved in other studies with a variety of BC quantification methodologies (e.g. Schauer et al., 2003; Schmid et al., 2001; Hammes et al., 2007).

\section{3. ${ }^{14} \mathrm{C}$ analysis}

The results of the ${ }^{14} \mathrm{C}$ measurements are listed in table 3. Results for the MA charcoal residue extracted by hypy $\left(51,200 \pm 1100{ }^{14} \mathrm{C} \mathrm{BP}\right.$; figure $\left.4(\mathrm{~A})\right)$ are consistent with previous measurements of this sample (Table 1). ${ }^{14} \mathrm{C}$ measurement of the untreated sample is also consistent with these analyses, demonstrating that for this sample, the level of environmental contamination does not significantly affect its ${ }^{14} \mathrm{C}$ age. Results for the aliquot of MA (OxA$16319 ; 46,600 \pm 700{ }^{14} \mathrm{C} \mathrm{BP}$ ) that had been subject to $0.5 \mathrm{M} \mathrm{HCl}$ digestion and deionized $\mathrm{H}_{2} \mathrm{O}$ washing prior to $\mathrm{ABA}$ pre-treatment and ${ }^{14} \mathrm{C}$ measurement do however suggest either that this $(0.5 \mathrm{M} \mathrm{HCl}$ digestion), or the $\mathrm{ABA}$ treatment itself, introduces trace amounts of contamination. Analysis of the product of hypy (retained on silica following removal from the pyrogenic carbon sample) gives a ${ }^{14} \mathrm{C}$ age of $37,450 \pm 750{ }^{14} \mathrm{C} \mathrm{BP}$. This indicates that carbon contamination younger than the ${ }^{14} \mathrm{C}$ age of the initial sample, albeit present in small amounts, is removed in the hypy treatment.

${ }^{14} \mathrm{C}$ measurement of the untreated sample of CHA (figure 4(B)) shows that, in common with MA, environmental contamination by younger carbon does not significantly affect the bulk sample ${ }^{14} \mathrm{C} /{ }^{12} \mathrm{C}$ ratio, as this measurement, 32,370 $\pm 180 \mathrm{BP}(\mathrm{OxA}-\mathrm{V}-2211-17)$, is consistent with previous determinations performed within the laboratory intercomparison exercise (Cuzange et al., 2007). This conclusion was also drawn by Cuzange et al., (2007), following 
$347{ }^{14} \mathrm{C}$ measurement of the alkali-soluble fraction of Chauvet Cave charcoals, which were not 348 found to be significantly different from the purified charcoal following conventional pre349 treatment. Measurement of the aliquot of CHA subject to $0.5 \mathrm{M} \mathrm{HCl}$ treatment gives an age of $35031,990 \pm 180 \mathrm{BP}(\mathrm{OxA}-17090)$ following ABA pre-treatment and 31,150 $\pm 250 \mathrm{BP}(\mathrm{OxA}-\mathrm{V}-$ 351 2211-16) following hypy treatment. The products of hypy extraction of the CHA sample on 352 silica were dated to $28,050 \pm 310 \mathrm{BP}(\mathrm{OxA}-\mathrm{V}-2198-50)$, again significantly younger than that 353 of the hypy residue, indicating selective removal of contamination present in small amounts. 354 It is important also to note that, as well as younger contamination, samples may also be 355 affected by older exogenous carbon, with a lower ${ }^{14} \mathrm{C}$ activity to that of the sample. In the 356 case of CHA, the untreated ages appear slightly older than those subject to pre-treatment, 357 which may indicate the presence of older, possibly geological, material.

359 Analysis of the high ${ }^{14} \mathrm{C}$ activity Holocene charcoal sample (CAS), presented in figure $4(\mathrm{C})$, 360 showed that again, environmental contamination present in the sample does not appear to be 361 sufficient to influence the ${ }^{14} \mathrm{C}$ age, as the age of the untreated sample $(2732 \pm 29 \mathrm{BP})$ is 362 within analytical error of the treated sample ages. In this instance, aliquots of CAS subject to $3630.5 \mathrm{M} \mathrm{HCl}$ treatment give similar ages whether treated by ABA $(2723 \pm 28 \mathrm{BP})$ or hypy $(2748$ $364 \pm 28 \mathrm{BP})$. In addition, the age of the material extracted by hypy onto silica (2732 $\pm 28 \mathrm{BP})$ is 365 also similar to that of the purified charcoals. This indicates that the non-BC material in this 366 sample is either not of a significantly different ${ }^{14} \mathrm{C}$ activity to that of the $\mathrm{BC}$ material fixed by 367 pyrolysis during sample formation, or is present in trace quantities insufficient to influence 368 the measured age of this more recent age sample. 


\section{Discussion}

372 The results show the potential for the hypy methodology to effectively isolate labile and resistant carbon fractions, from both individual samples of pyrolysed biomass and complex BC-containing matrices such as soil. The TOC profiles for soil and charcoal samples show that it is possible to identify a set of conditions for hypy analysis under which lignocellulosic and other easily convertible organic carbon material (e.g. lipids, proteins) are fully removed, but at which degradation of the resistant $\mathrm{BC}$ component of the sample has not yet commenced. This in turn appears to facilitate the removal of contaminating carbon compounds with a different ${ }^{14} \mathrm{C}$ activity to that of the hypy residue sample fraction, as seen in the ${ }^{14} \mathrm{C}$ measurement of the products removed from the MA and CHA samples onto silica during hypy treatments, which are significantly younger than the hypy residue samples. This suggests that the hypy process is able to selectively remove contaminating carbon from the charcoal samples, while minimizing potential sample loss, as the maximum sample BC content is recovered via this method.

386 In the case of MA, the introduction of carbonaceous material with a different ${ }^{14} \mathrm{C}$ age to that of the resistant $\mathrm{BC}$ sample fraction appears to influence the sample ${ }^{14} \mathrm{C}$ age following standard ABA pre-treatment, although this is not apparent in the case of CHA. Hatté et al. (2001) suggested that during the $\mathrm{NaOH}$ step of the $\mathrm{ABA}$ pre-treatment atmospheric $\mathrm{CO}_{2}$ dissolved into the solution might become linked with electropositive ions or incorporated directly with functional groups within the sample. They found that final acidification with $\mathrm{HCl}$ was not sufficient to remove this and break these ionic links, but that $\mathrm{H}_{2} \mathrm{SO}_{4}$ or $\mathrm{ABOX}$ SC treatments were. The samples tested in this earlier study did not include pyrogenic carbon, and it is possible that similar trace contamination is responsible for the younger observed ${ }^{14} \mathrm{C}$ age of MA following ABA treatment. In both instances the hypy treatment appeared to remove contaminating carbon from the samples, yielding ages that are in accord with previous age measurements at several laboratories.

The ${ }^{14} \mathrm{C}$ age of the material removed by the hypy process from MA and $\mathrm{CHA}$, although higher than that of the residue, is still relatively ancient $(37,450 \pm 750 \mathrm{BP}$ and $28,050 \pm 310$ $\mathrm{BP}$ respectively). This indicates that the hypy process is removing parts of the sample matrix itself that are susceptible to contamination, leaving the inert portion unaffected. Following

403 formation by pyrolysis, charcoal may comprise a range of carbon species which are not all in 
condensed aromatic form and therefore may provide sites for the adsorption of contaminating carbon. If the ABA pre-treatment does not always fully remove these sample components, this may explain the younger age of the ABA treated MA charcoal, whereas hypy does seem to selectively target contaminants. One advantage of the method in this context is that material removed in the hypy process may itself be subject to further analysis as it is retained by cryogenic trapping. These results indicate the potential of hypy as a pre-treatment technique for ${ }^{14} \mathrm{C}$ age measurement of samples with a constrained, continuous formation period. This could be extended for separation of specific carbon fractions in more complex samples, such as soil, in order to calculate aspects such as cycling and turnover of the resistant carbon fraction. Effective application of hypy for these purposes however requires more extensive investigation to establish the technique in matrices containing more thermally labile organic carbon and carbonates.

It is important to note that, for the charcoal samples tested here, environmental contamination does not appear to have introduced a significant amount of extraneous carbon with a different ${ }^{14} \mathrm{C}$ age to that of the sample. Chauvet Cave is located within the deep karst development of the Ardèche Plateau (Mocochain et al., 2006), therefore input from geological ${ }^{14} \mathrm{C}$-dead carbonates to the sample during deposition is a possibility. The results from this study however support previous conclusions that if such contamination is present, it is in small amounts that do not significantly influence the overall sample ${ }^{14} \mathrm{C}$ activity (Cuzange et al., 2007). One possibility for the apparent absence of evidence for post-depositional environmental contamination in MA is a result of the emplacement of this sample in pyroclastic flow of poorly sorted pumicious lapilli and ash (Alloway et al., 2004) where processes such as organic carbon decomposition and soil carbon cycling have not provided a means for contamination. Interestingly, in the sample recovered from Holocene sediments modified by the presence of a human domestic fortified settlement (Valera, 1997), ${ }^{14} \mathrm{C}$ measurement of the untreated sample also indicates no evidence of environmental contamination, as the untreated and treated (both ABA and hypy) samples give the same age. In this instance, the ${ }^{14} \mathrm{C}$ age of the material removed during the hypy process is also indistinguishable from the treated and untreated sample ages, indicating that the amounts of contaminating material introduced during processing are very slight, and therefore insufficient to influence the age of much younger samples with high ${ }^{14} \mathrm{C}$ activity. 
437 For the tested materials, a final hold temperature of $\sim 550^{\circ} \mathrm{C}$ appears to represent the optimum 438 conditions where non-BC material is removed, but at which degradation of the resistant 439 sample fraction has not yet commenced. Identification of this phase is important, as it is the 440 initial phase following removal of labile carbon sample content that is of interest in BC 441 quantification with the hypy method, as quantification of sample BC following the onset of 442 hydrogasification of the resistant sample fraction would lead to underestimation of the sample $443 \mathrm{BC}$ content. The conditions identified in this study for identification of this phase are in 444 agreement with previous work on carbonaceous material (e.g. Roberts et al., 1995; Snape et 445 al., 1989). One potential benefit of hypy is therefore the ability to provide a methodology by 446 which uniform and standardized operating conditions can be used for isolation of BC from a 447 wide range of materials. In chemical oxidative degradation, it is apparent that the conditions 448 required to isolate the $\mathrm{BC}$ portion of specific samples vary widely depending upon the precise 449 sample composition. For example, oxidation times to isolate kerogen and BC in sediments 450 ranged from 10-20 hours depending upon the composition and reactivity of specific samples 451 (Lim and Cachier, 1996). This highlights a key difficulty with isolation of the full BC 452 component of different samples with the chemical oxidation methodology, namely of 453 determining how resistant a sample fraction has to be to be defined chemically as BC. For 454 example, in a recent study, Knicker et al., (2007) found that $12 \%$ of organic carbon derived 455 from plant waxes (i.e. non-BC) in specific biomass samples was resistant to chemical 456 oxidation due to hydrophobicity, rather than chemical resistance.

458 In hypy, the range of operating conditions required to reproducibly isolate only the 459 chemically resistant fraction in a range of sample materials appears to be relatively 460 constrained. Additionally, replicate analyses of MO indicate that the TOC measured in the 461 residue after hypy treatment is highly reproducible between different runs using the same 462 experimental conditions. Provided the sample is well homogenized prior to treatment, the 463 reproducibility of $\mathrm{BC}$ determinations on a single sample by this technique appears to be very 464 good. This indicates that a high degree of measurement precision can be achieved using the 465 hypy method in order to consistently remove the same (non-BC) components over different 466 runs using the same methodological protocol for a wide range of sample types. 


\section{Conclusions}

469

470 The fact that hypy can reduce labile organic matter to volatile products in a controlled manner makes it an attractive new approach for the rapid isolation of the most resistant carbon fraction from carbonaceous samples. This suggests that hypy represents a promising new approach not only for BC quantification as an end in itself, but also for ${ }^{14} \mathrm{C}$ dating where purified $\mathrm{BC}$ is the target material for dating. These two goals are combined in many research studies, for example in efforts to establish the persistence and resistance of $\mathrm{BC}$ in the environment, and to quantify $\mathrm{BC}$ production rates and turnover times over extended timescales. The findings obtained here for soils and charcoal, in conjunction with the

478 previously reported findings for lignocellulosic material, coals, and 479 petroleum source rocks, suggest that hydropyrolysis is potentially a precise method for BC 480 measurements in a range of sample materials. Further investigation of the applicability of 481 hypy for these purposes should focus upon additional characterization of the hypy solid 482 residue and products, particularly with use of spectroscopic methods, for example solid-state

$483{ }^{13} \mathrm{C}$ nuclear magnetic resonance, which have been useful within studies of a wide range of 484 BC-containing matrices (e.g. Simpson and Hatcher, 2004), Further investigation of hypy 485 applicability for ${ }^{14} \mathrm{C}$ measurement would benefit via analysis of $\mathrm{BC}$ materials previously 486 shown to have suffered modern contamination. It appears that the method is potentially particularly effective for pre-treatment of samples close to the ${ }^{14} \mathrm{C}$ dating limit, where even trace contamination may be sufficient to produce a significant shift in measured sample isotopic ratio. An important additional advantage of the hypy technique is that it allows retention of the non-BC component of a sample, which may then be subject to further analysis and measurement. In applying the method to ${ }^{14} \mathrm{C}$ pre-treatment of charcoal where sample size is not limiting, it may be advantageous to select a more aggressive hypy regime, leading to some removal of the most resistant carbon fraction itself by hydrogasification to ensure complete removal of all trace contaminants. However, it is also conceivable that the method could be used for simultaneous $\mathrm{BC}$ quantification and sample purification for ${ }^{14} \mathrm{C}$ analysis.

497 
499 Funding for this work was provided by NERC standard grant NE/C004531/1 'Charcoal

500 Degradation in Natural Environments'. C.H. Vane publishes with permission of the

501 Executive Director, British Geological Survey. The authors acknowledge Heléne Valladas,

502 Bruno David and Antonio Valera for kindly providing samples of archaeological charcoal for

503 analysis in this project, the staff of the Oxford Radiocarbon Accelerator Unit for analyses,

504 and coordinating members of the Black Carbon ring trial (Hammes et al., 2007) for samples

505 of soil standard BC reference materials.

506

\section{References}

Alloway, B. V., Pribadi, A., Westgate, J. A., Bird, M., Fifield, L. K., Hogg, A., Smith I. , 2004. Correspondence between glass-FT and AMS 14 C ages of silicic pyroclastic density current (PDC) deposits sourced from Maninjau caldera, west-central Sumatra. Earth and Planetary Science Letters 227, 121-133.

514 Bird, M.I., Moyo, E., Veenendaal, E., Lloyd, J.J., Frost, P., 1999. Stability of elemental carbon in a savanna soil. Global Biogeochem. Cycles 13, 923-932

Bird M.I., Turney, C.S.M., Fifield, L.K., Jones, R., Ayliffe, L.K., Palmer, A., Cresswell, R.G., Robertson, S., 2002. Radiocarbon analysis of the early archaeological site of Nauwalabila 1, Arnhem Land, Australia: Implications for sample suitability and stratigraphic integrity. Quaternary Science Reviews 21, 1061-1075.

C. Bolton, C. Riemer, C.E. Snape, R.J. O'Brien and R. Kandiyoti, Effect of carrier gas flow and heating rates in fixed-bed hydropyrolysis of coal, Fuel, 1987, 66, 1413-1417.

Brocks, J.J., Love, G.D., Snape, C.E., Logan, G.A., Summons, R.E. Buick, R., 2003. Release of bound aromatic hydrocarbons from late Archean and Mesoproterozoic kerogens via hydropyrolysis. Geochim Cosmochim Acta 67, 1521-1530.

530 Clottes, J., Chauvet, J-M., Brunel-Deschamps, E., Hillaire, C., Daugas, J-P., Arnold, M., 531 Cachier, H., Evin, J., Fortin, P., Oberlin, C., 1995. Les peintures paléolithiques de la Grotte 
532 Chauvet-Pont-d'Arc, à Vallon-Pont-d'Arc (Ardèche, France): datations directes et indirectes 533 par la méthode du radiocarbone. Comptes-rendus de l'Académie des Sciences de Paris $534320,1133-1140$.

536 Cornelissen, G., and Gustafsson, O., 2004. Importance of Unburned Coal Carbon, Black 537 Carbon, and Amorphous Organic Carbon to Phenanthrene Sorption in Sediments. Environ 538 Sci Technol. 39, $764-769$

540 Cornelissen, G., Gustafsson, O., Bucheli, T. D., Jonker, M. T., Koelmans, A. A., van Noort, 541 P. C., 2005. Extensive sorption of organic compounds to black carbon, coal, and kerogen in 542 sediments and soils: mechanisms and consequences for distribution, bioaccumulation, and 543 biodegradation. Environ Sci Technol. 39, 6881-6895.

545 Cuzange, M.T., Delque-Kolic, E., Goslar, T., Grootes, P.M., Higham, T., Kaltnecker, E., 546 Nadeau, M.J., Oberlin, C., Paterne, M., van der Plicht, J., Ramsey, C.B., Valladas, H., 547 Clottes, J., Geneste, JM., 2007. Radiocarbon intercomparison program for Chauvet Cave. 548 Radiocarbon 49, 339-347

Czimczik, C. I., and Masiello, C. A., 2007. Controls on black carbon storage in soils. Global Biogeochemical Cycles 21, p.GB3005.

Eckmeier, E., Gerlach, R., Skjemstad, J. O., Ehrmann, O., Schmidt, M. W. I., 2007. Only small changes in soil organic carbon and charcoal found one year after experimental slashand-burn in a temperate deciduous forest. Biogeosciences Discuss. 4, 595-614.

Garcia, M.-A., 2005. Ichnologie générale de la grotte Chauvet. Bull. Soc. Préhistorique Française 102, 103-108.

560 Gélinas, Y., Prentice, K.M., Baldock, J.A., Hedges, J.I., 2001. An improved thermal oxidation method for the quantification of soot/graphitic black carbon in sediments and soils. Environ. Sci. Technol. 35, 3519-3525.

564 Geneste, J.-M., 2005. L'archéologie des vestiges matériels dans la grotte Chauvet. Bull. Soc. 565 Préhistorique Française 102, 135-144. 
567 Gillespie, R., Hammond, A.P., Goh, K.M., Tonkin, P.J., Lowe, D.C., Sparks, R.J., Wallace, G., 1992. AMS radiocarbon dating of a Late Quaternary tephra site at Graham's Terrace, New Zealand. Radiocarbon 34, 21-28.

Hammes, K., Schmidt, M. W. I., Smernik, R. J., Currie, L. A., Ball, W. P., Nguyen, T. H., Louchouarn, P., Houel, S., Gustafsson, Ö., Elmquist, M., Cornelissen, G., Skjemstad, J. O., Masiello, C. A., Song, J., Peng, P., Mitra, S., Dunn, J. C., Hatcher, P.G., Hockaday, W. C., Smith, D. M., Christoph Hartkopf-Fröder, M., Axel Böhmer, M., Lüer, B., Huebert, B. J., Amelung, G W., Brodowski, S., Huang, L., Zhang, W., Gschwend, P. M., Flores-Cervantes, X., Largeau, C., Rouzaud, J.-N., Rumpel, C., Guggenberger, G., Kaiser, K., Rodionov, A., Gonzalez-Vila, F. J., Gonzalez-Perez, J. A., De La Rosa, J. M., Manning, D. A.C., LópezCapél, E., Ding, L., 2007. Comparison of quantification methods to measure fire-derived (black/elemental) carbon in soils and sediments using reference materials from soil, water, sediment and the atmosphere.

Global

Biogeochemical

Cycles 21, GB301610.1029/2006GB002914. redating of contaminated samples from a tropical volcano: the Mansion "Series" of St. Kitts, West Indies. Bull. Volcanol. 56, 326-334.

Hatté, C., Morvan, J., Noury, C, Paterne, M., 2001. Is classical Acid-Alkali-Acid treatment responsible for contamination? An alternative proposition. Radiocarbon 43, 177-82.

Knicker, H., Müller, P., Hilscher, A., 2007. How useful is chemical oxidation with dichromate for the determination of "Black Carbon" in fire-affected soils? Geoderma 142, 178-196.

Kuhlbusch, T. A. J., 1995. Method for determining black carbon in. residues of vegetation fires. Environ Sci Technol 29, 2695-2702.

Levine, J.S., 1991. Global biomass burning: Atmospheric, climatic, and biospheric implications. The MIT Press, Cambridge, Massachusetts. 
600 Lim, B., Cachier, H., 1996. Determination of black carbon by chemical oxidation and thermal 601 treatment in recent marine and lake sediments and Cretaceous-Tertiary clays. Chemical 602 Geology 131, 143-154.

603

604 Love, G.D., Snape, C.E., Carr, A.D., Houghton, R.C., 1995. Release of covalently-bound 605 alkane biomarkers in high yields from kerogen via catalytic hydropyrolysis. Organic 606 Geochemistry 23, 981-986.

607

608 Love, G.D., McAulay, A., Snape, C.E., Bishop, A.N., 1997. Effect of process variables in 609 catalytic hydropyrolysis on the release of covalently-bound aliphatic hydrocarbons from 610 sedimentary organic matter. Energy Fuels 11, 522-531.

611

612 Meredith, W., Russell, C.A., Cooper, M., Snape, C.E., Love, G.D., Fabbri, D., Vane, C.H., 613 2004. Trapping hydropyrolysates on silica and their subsequent thermal desorption to 614 facilitate rapid fingerprinting by GC-MS. Org. Geochem. 35, 73-89.

615

616 Mocochain, L., Clauzon, G., Bigot, J.-Y., 2006. Réponses de l'endokarst ardéchois aux 617 variations eustatiques générées par la crise de salinité messinienne. Bull. Soc. géol. Fr., 177, $618 \quad 27-36$.

619

620 Pietikäinen, J., Kiikkilä, O., Fritze, H., 2000. Charcoal as a habitat for microbes and its effect 621 on the microbial community of the underlying humus. Oikos, 89, 231-242.

622

623 Preston, C. M., Schmidt, M. W. I., 2006. Black (pyrogenic) carbon: a synthesis of current 624 knowledge and uncertainties with special consideration of boreal regions. Biogeoscience 3 , $625397-420$.

626

627 Rawlins, B.G., Vane, C.H., Kim, A.W., Tye, A.M., Kemp, S., Bellamy, P.H., 2008. Methods 628 for estimating types of soil organic carbon and their application to surveys of UK urban areas. 629 Soil Use and Management. DOI: 10.1111/j.1475-2743.2007.00132.x 630

631 Roberts, M. J., Snape, C.E., Mitchell, S.C., 1995. Hydropyrolysis: fundamentals, two-stage 632 processing and PDU operation. In Snape C.E. (Ed.), Geochemistry, Characterisation and 633 Conversion of Oil Shales. NATO ASI Series Vol. C455, Kluwer, pp. 277-294. 
635 Rocha, J.D., Luengo, C.A., Snape, C.E., 1999. The scope for generating bio-oils with 636 relatively low oxygen contents via hydropyrolysis. Organic. Geochemistry 30, 1527-1534.

638 Sander, M., Pignatello, J. J., 2005. Characterization of Charcoal Adsorption Sites for 639 Aromatic Compounds: Insights Drawn from Single-Solute and Bi-Solute Competitive 640 Experiments Environ. Sci. Technol., 39, 1606 -1615.

641

642 Santos, G.M., Bird, M.I., Pillans, B., Fifield, L.K., Alloway, B.V., Chappell, J., Hausladen, 643 P.A., Arneth, A., 2001. Radiocarbon dating of wood using different pre-treatment procedures: 644 Application of the chronology of Rotoehu ash, New Zealand. Radiocarbon 43, 239-248.

646 Schauer, J. J., Mader, B. T., Deminter, J. T., Heidemann, G., Bae, M. S., Seinfeld, J. H., 647 Flagan, R. C., Cary, R. A., Smith, D., Huebert, B. J., Bertram, T., Howell, S., Kline, J. T., 648 Quinn, P., Bates, T., Turpin, B., Lim, H. J., Yu, J. Z., Yang, H., Keywood, M. D., ACE-Asia , 649 2003. Intercomparison of a thermal-optical method for the determination of particle-phase 650 organic and elemental carbon. Environmental Science \& Technology 37, 993 - 1001.

Schmid, H., Laskus, L., Abraham, H. J., Baltensperger, U., Lavanchy, V., Bizjak, M., Burba, P., Cachier, H., Crow, D., Chow, J., Gnauk, T., Even, A., Brink, H. M. T., Giesen, K.-P., Hitzenberger, R., Hueglin, C., Maenhaut, W., Pio, C., Carvalho, A., Putaud, J.-P., ToomSauntry, D., Puxbaum, H., 2001. Results of the "carbon conference" international aerosol carbon round robin test Stage I. Atmospheric Environment 35, 2111 - 2121.

Schmidt, M.W.I., Skjemstad, J.O., Gehrt, E., Kögel-Knabner, I., 1999. Charred organic 659 carbon in German chernozemic soils. European Journal of Soil Science 50, 351-365.

Schmidt et al., 2001 M.W.I. Schmidt, J.O. Skjemstad, C.I. Czimczik, B. Glaser, K.M. Prentice, Y. Gelinas and T.A.J. Kuhlbusch, Comparative analysis of black carbon in soils, organic matter. Naturwissenschaften 91, 436-440. 
668 Skjemstad, J.O., Taylor, J.A., Smernik, R., 1999. Estimation of charcoal (char) in soils.

669 Communication in Soil science and Plant analysis 30, 2283-2298.

670

Skjemstad, J. O., Reicosky, D. C., Wilts, A. R., McGowan, J. A., 2002. Charcoal Carbon in US Agricultural Soils. Soil Sci. Soc. Am. J. 66, 1249-1255.

Snape, C.E., Bolton, C., Dosch, R.G., Stephens, H.P., 1989. High liquid yields from bituminous coal via hydropyrolysis with dispersed catalysts. Energy \& Fuels 3, 421-425.

676

Suzuki, T., Yamada, T., Homma, T., 1986. Hydrogasification of wood for high heating-value gas production, 3: Relationship between $\mathrm{Ni}$ catalyst loading and the reactivity on $\mathrm{CH} 4$ production in low-temperature hydrogasification of wood charcoal. Journal of the Japan Wood Research Society. 32, 730-737.

681

Tang, M. M., and Bacon, R., 1964. Carbonization of cellulose fibres-I low temperature 683 pyrolysis. Carbon 2, 211-220.

684

685

Turney, C.S.M., Bird, M.I., Fifield, L.K., Roberts, R.G., Smith, M.A., Dortch, C.E., Grün, 686 R., Lawson, E., Miller, G.H., Dortch, J. Cresswell, R.G., Ayliffe, L.K., 2001. Breaking the 687 radiocarbon barrier and early human occupation at Devil's Lair, southwestern Australia. Quat. Res. 55, 3-13.

689

690 Valera, A. C., 1997. O Castro de Santiago (Fornos de Algodres, Guarda). Aspectos da 691 calcolitização da bacia do alto Mondego. Lisboa: Câmara Municipal de Fornos de Algodres

692 Valladas, H., Clottes, J., Geneste, J.-M., Garcia, M.-A., Arnold, M., Cachier, H., Tisnérat693 Laborde, N., 2001. Evolution of prehistoric cave art. Nature 413, 479.

694 Valladas, H., Tisnérat-Laborde, N., Cachier, H., Kaltnecker, E., Arnold, M., Oberlin, C., 695 Evin, J., 2005. Bilan des datations carbone 14 effectuées sur des charbons de bois de la grotte 696 Chauvet. Bull. Soc. Préhistorique Française 102, 109-113.

697 Wang, X. C., Zhang, Y. X., Chen, R. F., 2001. Distribution and partitioning of polycyclic 698 aromatic hydrocarbons (PAHs) in different size fractions in sediments from Boston Harbour, 699 United States. Mar Pollut Bull 42, 1139-1149. 
701 Wardle, D.A., Zackrisson, O., Nilsson, M.-C., 1998. The charcoal effect in boreal forests:

702 mechanisms and ecological consequences. Oecologia 115, 419-426.

703

704 Warnock D.D, Lehmann J, Kuyper T.W and Rillig M.C. 2007. Mycorrhizal responses to 705 biochar in soil - concepts and mechanisms. Plant and Soil. 300, 9-20.

706

707 Wild, E.M., Neugebauer-Maresch, C., Einwögerer, T., Stadler, P., Steier, P., and Brock, F., 708 2008. 14C-Dating of the Upper Paleolithic Site at Krems-Hundssteig in Lower Austria. 709 Radiocarbon, 50, 1-10.

710

711 W.-C. Xua, K. Matsuoka, H. Akiho, M. Kumagai, A. Tomita, High pressure hydropyrolysis 712 of coals by using a continuous free-fall reactor, Fuel, 2003, 82, 677-685 . 


\section{Figure legends}

716 Figure 1: Schematic representation of the hypy apparatus, showing flow of high hydrogen gas

717 pressure through the system (dashed arrows).

719 Figure 2: Variation of residue TOC from hypy for the reference soil samples VER (top) and 720 BGS (bottom), showing the zone of labile C loss (A), plateau of TOC content (B) and onset 721 of sample hydrogasification (C).

723 Figure 3: Weight loss (black diamonds) and residue TOC (grey squares) for the MA 724 (Maninjau) natural charcoal sample, showing the zone of labile C loss (A), and plateau of 725 TOC content (B). Note that for this sample, the apparent plateau at higher temperatures may 726 represent delayed onset of hydrogasification relative to that evident in figure 2.

728 Figure $4:{ }^{14} \mathrm{C}$ measurement results of the charcoal samples following no treatment, and pretreatment with standard ABA and hypy methodologies. For samples treated by hypy both the

730 products removed from the charcoal during treatment (product), and the $\mathrm{BC}$ residue 731 following hypy were analysed. Samples are presented in order of age, where A: MA, B: 732 CHA, and C: CAS. 
736 Table 1: Details of sample materials selected for hypy treatment and analysis within this 737 study.

739 Table 2: TOC (\%) of the BC residues following hypy treatment for samples of two reference 740 soils (VER and BGS) and one natural charcoal (MA).

742 Table 3: Results of AMS ${ }^{14} \mathrm{C}$ measurements on three natural/archaeological charcoals 743 following treatment by standard ABA methodology and hypy. For samples treated by hypy 744 both the products removed from the charcoal during treatment (product), and the BC residue 745 following hypy were analysed. No treatment indicates the measurement of the charcoal 746 sample directly after extraction from deposition sediments (i.e. no laboratory treatment). 